\title{
Synthesis and characterization of silver nanoparticles loaded poly(vinyl alcohol)-lignin electrospun nanofibers and their antimicrobial activity
}

\author{
Aadil, Keshaw Ram; Mussatto, Solange I.; Jha, Harit
}

Published in:

International Journal of Biological Macromolecules

Link to article, DOI:

10.1016/j.ijbiomac.2018.08.109

Publication date:

2018

Document Version

Peer reviewed version

Link back to DTU Orbit

Citation (APA):

Aadil, K. R., Mussatto, S. I., \& Jha, H. (2018). Synthesis and characterization of silver nanoparticles loaded poly(vinyl alcohol)-lignin electrospun nanofibers and their antimicrobial activity. International Journal of Biological Macromolecules, 120(Part A), 763-767. https://doi.org/10.1016/j.ijbiomac.2018.08.109

\section{General rights}

Copyright and moral rights for the publications made accessible in the public portal are retained by the authors and/or other copyright owners and it is a condition of accessing publications that users recognise and abide by the legal requirements associated with these rights.

- Users may download and print one copy of any publication from the public portal for the purpose of private study or research.

- You may not further distribute the material or use it for any profit-making activity or commercial gain

- You may freely distribute the URL identifying the publication in the public portal 


\section{Accepted Manuscript}

Synthesis and characterization of silver nanoparticles loaded poly(vinyl alcohol)-lignin electrospun nanofibers and their antimicrobial activity

Keshaw Ram Aadil, Solange I. Mussatto, Harit Jha

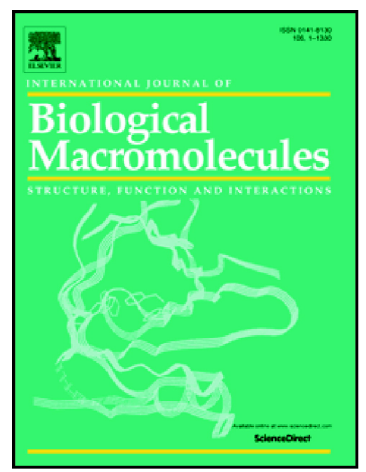

PII: $\quad$ S0141-8130(18)32727-2

DOI: $\quad$ doi:10.1016/j.ijbiomac.2018.08.109

Reference: $\quad$ BIOMAC 10353

To appear in: International Journal of Biological Macromolecules

Received date: $\quad 5$ June 2018

Revised date: $\quad 7$ August 2018

Accepted date: $\quad 21$ August 2018

Please cite this article as: Keshaw Ram Aadil, Solange I. Mussatto, Harit Jha, Synthesis and characterization of silver nanoparticles loaded poly(vinyl alcohol)-lignin electrospun nanofibers and their antimicrobial activity. Biomac (2018), doi:10.1016/ j.ijbiomac.2018.08.109

This is a PDF file of an unedited manuscript that has been accepted for publication. As a service to our customers we are providing this early version of the manuscript. The manuscript will undergo copyediting, typesetting, and review of the resulting proof before it is published in its final form. Please note that during the production process errors may be discovered which could affect the content, and all legal disclaimers that apply to the journal pertain. 


\title{
Synthesis and characterization of silver nanoparticles loaded poly (vinyl alcohol)-lignin electrospun nanofibers and their antimicrobial activity
}

\author{
Keshaw Ram Aadil ${ }^{1 *}$, Solange I. Mussatto ${ }^{2}$, Harit $\mathrm{Jha}^{3}$ \\ ${ }^{1}$ Department of Biotechnology, National Institute of Technology-Raipur, Raipur, 492010, \\ Chhattisgarh, India \\ ${ }^{2}$ Novo Nordisk Foundation Center for Biosustainability, Technical University of Denmark, \\ Kemitorvet, Building 220, 2800, Kongens Lyngby, Denmark \\ ${ }^{3}$ Department of Biotechnology, Guru Ghasidas Vishwavidyalaya (A Central University), \\ Bilaspur-495009, Chhattisgarh, India
}

*Corresponding author: Tel.: 09770130757 (M); +91-7752 260405 (O); fax: +91-7752 260148.

E-mail addresses:

kaadil7@gmail.com (K.R. Aadil)

smussatto@biosustain.dtu.dk (S.I. Mussatto)

harit74@yahoo.co.in (H. Jha) 


\section{ABSTRACT}

In the present study, poly (vinyl alcohol) (PVA)- Acacia lignin (PL) nanofiber mats loaded with silver nanoparticles were prepared and characterized. In-situ synthesis of silver nanoparticles was accomplished using alkali lignin extracted from Acacia wood as a reducing agent. Ultrafine nanofiber mats of PL incorporated with silver nanoparticles were fabricated using the electrospinning technique. The fiber morphology of the resultant nanofiber was characterized using scanning electron microscopy. The average diameter of the nanofiber was in the range of 100 to $300 \mathrm{~nm}$. The existence of silver nanoparticles was confirmed by X-ray diffraction analysis. The influence of silver nanoparticles on the polymer structure was investigated by mechanical and thermal properties analysis. The antimicrobial activity of the PL nanofibers containing silver nanoparticles was tested against Bacillus circulans (MTCC 7906) and Escherichia coli (MTCC 739) and showed significant results against both microorganisms. The results revealed that PL nanofiber containing silver nanoparticles may have potential applications as membrane filtration, antimicrobial fabrics and wound dressing material.

Keywords: Lignin nanofiber; Electrospinning; Silver nanoparticles; Antimicrobial activity 


\section{Introduction}

Environmental concerns and depletion of fossil fuel have driven research attention on natural polymers and composites due to their renewable and biodegradable properties. In this sense, lignin, which is the second most abundant renewable biopolymer present in lignocellulosic biomass (Kai et al., 2016; Aadil et al., 2016; Mussatto and Dragone, 2016) and a major by-product of pulp-paper and biofuel production industries, has attracted great attention since it is available in huge amount and still underutilized for valuable applications.

Lignin is a polyphenolic macromolecule of very complex structure, which comprises three main monomers ( $p$-coumaryl alcohol, coniferyl alcohol and sinapyl alcohol) and different functional groups (such as phenolic and aliphatic hydroxyls, methoxyl and carboxyl) that interact with various polymers and form a stable polymer complex (Aadil et al., 2014; Saini et al., 2015; Mussatto et al., 2007). Due to its characteristics and properties, lignin has been studied as a raw material for the production of ecofriendly polymers composites, carbon fibers, value-added chemicals and resins (Bahi et al., 2017; Figueiredo et al., 2018).

Lignin extracted from various sources have been blended with different synthetic polymers such as poly(vinyl alcohol), polyethylene terephthalate, polyethylene oxide (PEO), polypropylene (Kadla et al., 2002; Kubo and Kadla, 2005) and biodegradable biopolymers like alginate, bacterial cellulose, gelatin, soya protein, poly(lactic acid) (Aadil et al., 2016a, 2016b; Kai et al., 2016, Culebras et al., 2015) to make ecofriendly composites. In previous studies, alginate, bacterial cellulose, gelatin, chitosan and collagen based nanofiber scaffolds were widely used for biomedical and tissue engineering applications. However, there are limited reports on the fabrication of lignin nanofibers. According to the literature, lignin has 
been blended with cellulose nanocrystal, soya protein and poly (lactide) to make nanofiber or carbon fibers (Ago et al., 2012; Salas et al., 2014; Kai et al., 2016). Nevertheless, due to less viscosity and complex polymer structure of lignin, electrospinning of alone lignin is difficult. Hence, to make smooth fiber various synthetic polymers such as poly(alcohol), poly(lactic acid) and poly(ethylene oxide) have been blended (Kai et al., 2016). Recently, Culebras and his team fabricated organosolv lignin based carbon fiber by blending with polyurethane (Culebras et al., 2018).

Electrospinning has proved to be a simple and effective technique for the production of nano-sized fibers of polymers, inorganic materials, and organic/inorganic composites (Huang et al., 2003). Once a high voltage is applied to the needle of a syringe containing a precursor solution, the solution is ejected from the needle and deposited as a nonwoven fibrous mat on a substrate placed on the ground collector. Electrospun fibers have unique properties like high specific surface areas $\left(10-1000 \mathrm{~m}^{2} \mathrm{~g}^{-1}\right)$ (Kalra et al., 2009) high aspect ratios, high porosities (up to $80 \%$ ) (Yoon et al., 2008) and controllable diameters that range from nanometers to microns, which make them perfect materials for the multifaceted applications. Threedimensional fibrous structures of electrospun fibers are flexible and can thus be manufactured into different shapes. Additionally, it is also possible to control the fiber composition and surface chemistry by blending, encapsulation, and immobilization of biological and other material components (Huang et al., 2003; Meli et al., 2010; Agarwal et al., 2013).

This work describes the manufacture of Acacia lignin based electrospun nanofibers. A fiber forming water soluble PVA and in-situ synthesized silver nanoparticles (AGNPs) were added at minimum levels to support electrospinning of Acacia lignin into PVA-lignin-AGNP hybrids nanofiber. The fiber morphology of the resultant nanofiber was characterized using scanning electron microscopy (SEM) and transmission electron microscopy (TEM). The structural and crystalline nature of the electrospun nanofiber mat was studied by X-ray 
diffraction analysis and the thermal stability was evaluated by thermal gravimetric analysis (TGA). In addition, antimicrobial activity of the PL nanofibers containing silver nanoparticles was also investigated against gram positive and negative bacteria.

\section{Materials and Methods}

\subsection{Raw material and chemicals}

Acacia nilotica wood powder (18 mesh size) was collected from the local timber mill of Bilaspur, Chhattisgarh, India. Poly(vinyl alcohol) (PVA) (Mw: 30000-70000), silver nitrate $\left(\mathrm{AgNO}_{3}\right)$, sodium hydroxide were purchased from Sigma-Aldrich, USA. All other chemicals and reagents used were of analytical grade and purchased from Hi-Media Chemical Pvt. Ltd. Mumbai, India. Ultra-pure water (Elix, Merck Milipore, India) was used through the experiment.

\subsection{Lignin extraction}

Lignin was recovered from Acacia wood powder by soxhlet extraction using acetone $(60 \% \mathrm{v} / \mathrm{v})$ in a solid/liquid ratio of $1: 10(\mathrm{~g} / \mathrm{ml})$ at $60{ }^{\circ} \mathrm{C}$ for $5 \mathrm{~h}$. Lignin was then recovered from the extract by evaporating the solvent followed by drying in oven (Aadil et al., 2014). The physicochemical and biological properties of the recovered lignin was previously reported (Aadil et al., 2014; Barapatre et al., 2015; Aadil et al., 2016).

\subsection{Preparation of poly (vinyl alcohol)-lignin-silver nanoparticles blend (PLS)}

In order to prepare the PVA-lignin blend, PVA (10 wt\%) and lignin (1 wt $\%)$ were blended in a 9:1 ratio in $10 \mathrm{~mL}$ of methanol: water $(60: 40)$ and stirred for $2 \mathrm{~h}$ to obtain a homogenous solution. Subsequently, lignin stabilized silver nanoparticles were synthesized as described by Aadil et al. (2016) and added into the polymers blend solution. The mixture was 
vigorously stirred for $1 \mathrm{~h}$ to obtain a homogenous solution. Finally, the homogeneous solution was sonicated for 10 min using an ultrasonic homogenizer (BioLogics Inc, USA, Model: 3000) to remove trap air bubbles. A schematic representation of the fabrication of silver nanoparticles loaded PL nanofibers is shown in Fig. 1.

\section{Figure 1}

\subsection{Electrospinning}

Electrospinning experiment was carried out in an ESPIN NANO equipment (PECO, Chennai, India). The spinning solution was transferred to $2 \mathrm{ml}$ plastic syringe having 22 gauge needle diameter. The distance between the needle and the collector was set at $12 \mathrm{~cm}$. The assembly was in perpendicular position with respect to the syringe. A voltage of $15 \mathrm{kV}$ was applied for the nanofibers production, while a flow rate of $10 \mu \mathrm{L} / \mathrm{min}$ was set for the polymer solution delivery using the syringe pump. The fibers were collected in an aluminum sheet coated rotating drum (diameter: $6 \mathrm{~cm}$, length: $15 \mathrm{~cm}$ ) with high rotating speed of $800-$ $1000 \mathrm{rpm}$. Sample was peeled out and dried in a vacuum oven at $80{ }^{\circ} \mathrm{C}$ for $5 \mathrm{~h}$ to remove the residual solvent.

\subsection{Characterization of electrospun nanofibers}

In order to study the hydrophilic and hydrophobic nature of PLS nanofiber mat, contact angle analysis (Pheonix 300) was performed at room temperature. Nanofiber mat sample was cut into $1 \mathrm{x} 1 \mathrm{~cm}$ and put on the sample holder. Images of the water droplet on mat were taken after $5 \mathrm{~s}$ of contact time. The hydrophilicity of the fiber mat was measured by the acquired images.

Morphology of PLS nanofibers was verified by SEM analysis using a JEOL equipment, model JSM-6390LV. Fiber samples were put on a metal stub and platinum coated 
by using sputter coating technique for $20 \mathrm{~s}$ to make them conducting. Images of fibers were taken at $20 \mathrm{kV}$ accelerating voltage at $10 \mathrm{~K}$-fold magnification. The elemental composition and presence of silver were confirmed by EDX analysis (INCA 250 EDS with X-MAX 20 mm Detector). Further, the size, shape and morphology of incorporated silver nanoparticles was studied by transmission electron microscopy (TEM) (JEOL microscope JEM 2100). TEM specimen was prepared through casting a drop of the suspension on a carbon coated copper grid. The surplus solution was removed from the grid by tissue paper and dried overnight at room temperature $\left(25 \pm 2{ }^{\circ} \mathrm{C}\right)$. The sample was then observed under the microscope at an accelerating voltage of $200 \mathrm{KV}$ with different magnifications.

Thermal stability was studied using a thermo-gravimetric analyzer (Diamond STA6000, Perkin-Elmer, Shelton, USA) under nitrogen atmosphere at a flow rate of $200 \mathrm{~mL} / \mathrm{min}$. Samples (about $5 \mathrm{mg}$ ) were heated from ambient temperature to $700{ }^{\circ} \mathrm{C}$ at a heating rate of 10 ${ }^{\circ} \mathrm{C} /$ min to obtain individual spectra. Wide angle XRD study of nanofibers mat was carried out in order to examine the crystallinity and the presence of silver nanoparticles in the nanofibers. The samples were analyzed using a Bruker AXS D8 Advance X-ray diffractometer system. The radiation was $\mathrm{Cu} \mathrm{K \alpha}(\lambda=1.5406 \AA)$ with $40 \mathrm{kV}$ voltage and $35 \mathrm{~mA}$ intensity.

\subsection{Antimicrobial activity of lignin-PVA-AGNP nanofiber mat}

The antimicrobial activity of AGNP loaded PLS nanofiber was tested by agar well diffusion method against the gram-positive and gram-negative bacteria Bacillus circulans (MTCC 7906) and Escherichia coli (MTCC 739), respectively. Pure culture of bacteria were cultivated on nutrient agar medium. Bacterial strains were swabbed uniformly onto the plates using sterile cotton swabs. Subsequently, the nanofiber mat of $1 \times 1 \mathrm{~cm}$ in size were placed on the top of agar medium containing bacterial culture. The zone of inhibition were observed 
after $24 \mathrm{~h}$ of incubation at $37^{\circ} \mathrm{C}$. The data were expressed as mean $\pm \mathrm{SD}$ of three independent experiments.

\section{Results and discussion}

The visual appearance of the prepared electrospun nanofiber mat was yellow and uniform (Fig. 2A). The yellow color was due to the presence of lignin and silver nanoparticles in the fibers. The formation of uniform mat suggests a good miscibility of the lignin with PVA.

The morphology, surface structure and dimension of nanofibers was observed by SEMEDX at different magnifications. SEM images of the prepared PLS nanofibers indicates that fibers were uniform in size and oriented in 3D angle (Fig. 2B). The diameter of the fibers was between 128 and $291 \mathrm{~nm}$. The elemental composition of the fibers, determined by EDX analysis, confirmed the presence of silver at $2.984 \mathrm{KeV}$ (Fig. 2C). Carbon content of the fibers was high, corresponding to approximately $88.33 \%(\mathrm{w} / \mathrm{w})$. The presence of carbon in such amount in PLS fiber suggests its potential for application in the synthesis of carbon fibers (Figueiredo et al., 2018). Further, the image of contact angle was shown in Fig. 2D, the mean contact angle of PVA-lignin nanofiber was $61.9 \pm 2$, suggesting hydrophilic nature of nanofiber mat. PVA and lignin both have high surface energy, thus their composites show hydrophilic nature.

\section{Figure 2}

The presence and distribution of the silver nanoparticles on PLS nanofiber was confirmed using TEM analysis (Fig. 3A-F). TEM study revealed that the silver nanoparticles are almost polydispersed in nature with spherical and oval shape (Fig.3B-C). Silver nanoparticles are randomly distributed on PLS nanofiber. As per our previous study, the 
diameter of lignin stabilized silver nanoparticle were ranging from 10-50 nm (Aadil et al. 2016). Further, no particle aggregation was observed, which suggest the stability of the nanoparticles. The faces of silver nanoparticle were clearly visible in the Fig. 3D, suggesting face cubic structure of the particles. These results are consistent with our previous report describing the lignin stabilized silver nanoparticles (Aadil et al., 2016).

Figure 3

The presence of silver nanoparticles was further confirmed by XRD analysis. Fig. 4A, displays the XRD pattern of the PLS nanofiber with two characteristic diffraction peaks of silver nanoparticle at 33 and $47^{\circ}$ in the 2 theta region, which corresponds to (111) and (200) planes of silver, respectively. Thus, the XRD spectrum confirmed the presence of silver nanoparticles. These values are in agreement with those reported for face centric cubic (FCC) structure of silver by Joint Committee on Powder Diffraction Standards File No. 04-0783 (Aadil et al., 2016).

Thermal stability is a very important property for material use in packaging and biomedical applications (Aadil et al., 2016). The TGA and differential thermal analysis (DTA) curves of PLS nanofibers are shown in Fig. 4B. As can be seen, the maximum weight loss percentage was observed between 200 and $300{ }^{\circ} \mathrm{C}$, with maximum degradation rate at $280.94{ }^{\circ} \mathrm{C}$ (weight loss rate of $-0.988 \mathrm{mg} / \mathrm{min}$ ), which is probably associated with the decomposition of C-C bonds in lignin. After $300^{\circ} \mathrm{C}$, a slight weight loss was observed until $450{ }^{\circ} \mathrm{C}$, which can be attributed to the degradation of lignin molecules. The weight loss under the highest temperature stage $\left(\mathrm{T}>550{ }^{\circ} \mathrm{C}\right)$ is associated to the degradation of thermally stable structure produced due to crosslinking reaction. At $700{ }^{\circ} \mathrm{C}$, about $75 \%$ weight loss was observed, suggesting the presence of inorganic and charred compounds in the sample.

\section{Figure 4}


Antimicrobial activity of PLS nanofiber was studied after $24 \mathrm{~h}$ of incubation at $37{ }^{\circ} \mathrm{C}$. The plates in which well diffusion was carried out were observed for the presence of growth inhibition zone around the placed nanofiber mat and control antibiotic (Fig. 5). Results revealed that nanofiber mat was effective against both bacterial strains. The size of inhibition zone observed against gram negative E.coli and gram positive B. circulans was $1.1 \pm 0.05$ and $1.3 \pm 0.08 \mathrm{~cm}$, respectively. These results suggest that silver nanoparticle loaded PLS nanofiber exhibited good antimicrobial activity, which is probably due to its large surface area, small size and spherical shape. These results establish that the AGNPs are distributed on the fiber surface and are active. It was suggested that the silver nanoparticles inhibit the permeability and respiration process of the bacteria by attaching to the surface of the cell membrane and disturb its power function (Bindhu et al., 2014). Previous report on antimicrobial activity of silver nanoparticles suggested that small size particles have more antimicrobial activity due to its larger surface area (Baker et al., 2005). Moreover, due to the presence of phenolic compound, lignin itself act as an antimicrobial agent. The polyphenolic group of lignin is known to damage bacterial cell membrane and subsequently, release of cellular components and cell lysis (Dong et al., 2011). This outcome suggests it putative application in the development of antimicrobial non-woven fiber, which could be useful for textile and biomedical, particularly wound healing applications.

\section{Figure 5}

\section{Conclusion}

Poly(vinyl alcohol)-lignin nanofiber mats loaded with silver nanoparticles was successfully fabricated using the electrospinning technique. The average diameter of the nanofiber was in the range of 100 to $300 \mathrm{~nm}$ and the visual appearance of the electrospun 
nanofiber mat was yellow and uniform, revealing good miscibility of the lignin and silver nanoparticles with PVA. The antimicrobial activity of the PVA-lignin nanofibers containing silver nanoparticles revealed growth inhibition zone against Bacillus circulans and Escherichia coli. These results suggest that PVA-lignin nanofiber containing silver nanoparticles may have potential applications as membrane filtration, antimicrobial fabrics, wound dressing material and in other biomedical applications, which will be explored in the near future.

\section{Acknowledgements}

This study was funded by Science and Engineering Research Board (SERB), New Delhi, India under the National Post-Doctoral Fellowship (NPDF) scheme (PDF/2016/001156) to KRA. This study was also supported by University Grant Commission (UGC), New Delhi, India - vide nos. F.41-543/2012 (SR)) and DBT BUILDER (BT/PR 7020/INF/22/172/2012). The authors also gratefully acknowledge the Novo Nordisk Foundation (Denmark, NNF Grant number: NNF10CC1016517), STIC Cochin for thermal and XRD analysis. Prof. Natarajan TS (Department of Physics, Indian Institute of Technology-Madras, Chennai) for providing the electrospinning facility, and the Head of Department of Biotechnology for his kind support and extending the laboratory facility.

\section{References}

1. A. Bahi, J. Shao, M. Mohseni, F.K.Ko, Sepa. and Purif. Tech. 187 (2017) 207-213.

2. C. Baker, A. Pradhan, L. Pakstis, J.P. Darrin, S. S. Ismat, J. Nanosci. Nanotechnol. 5, (2005)

244-249.

3. D. Kai, W. Ren, L. Tian, P. Chee, Y. Liu, S. Ramakrishna, X. J. Loh. ACS Sustainable Chem. 
Eng.4 (10) (2016) 5268-5276.

4. J. F. Kadla, S. Kubo, R. A. Venditti, R. D. Gilbert, A. L. Compere and W. Griffith, Carbon, (2002) 40, 2913-2920.

5. J. L. Braun, K. M. Holtman and J. F. Kadla, Carbon, 43 (2005) 385-394.

6. K. Yoon, B. S. Hsiao and B. Chu, J. Mater. Chem., 18 (2008) 5326-5334.

7. K.R. Aadil, A. Barapatre, A.S. Meena, H. Jha, Inter. J. Biolog. Macromole. 82 (2016) 3947

8. K.R. Aadil, A. Barapatre, S. Sahu, H. Jha, B.N. Tiwary, Inter. J. Biolog. Macromole. 67 (2014) 220-227.

9. K.R. Aadil, D. Prajapati, H. Jha, Food Packaging and Shelf Life. 10 (2016) 25-33.

10. K.R. Aadil, Barapatre A, Jha H, Biores. and Biopro. 3(27) (2016) 1-11.

11. L. Meli, J. Miao, J. S. Dordick, and R. J. Linhardt. Green Chem. 12 (2010) 1883-1892.

12. M. Culebras, C. J. Grande, F. G. Torres, O. P. Troncoso, C. M. Gomez, M. C. Bañó. Inter. J. Polym. Mate. And Polym. Biomat., 64 (2015) 411-415.

13. M. Culebras, A. Beaucamp, Y. Wang, M. M. Clauss, E. Frank, and M. N. Collins. ACS Sustainable Chem. Eng., 6 (7), (2018) 8816-8825.

14. M.R. Bindhu, M. Umadevi, Spect. Act. part A:Mole. \& Biomole. Spect.128 (2014) 37-45.

15. P. Figueiredo, K. Lintinen, J.T. Hirvonen, M.A.Kostiainen, H.A. Santos, Prog. in Mat. Sci.,

93 (2018) 233-269.

16. S. Agarwal, A. Greiner, J.H. Wendorff. Progress in polymer science, 38 (2013) 963-991.

17. S.I. Mussatto, G.M. Dragone, Biomass pretreatment, biorefineries and potential products for a bioeconomy development. In: Biomass Fractionation Technologies for a Lignocellulosic Feedstock Based Biorefinery. Mussatto SI (Ed.), Elsevier Inc., Waltham, MA., (2016) 1-22. 
18. S.I. Mussatto, M. Fernandes, I.C. Roberto, Carbo. Polym., 70 (2007) 218-223.

19. S. Kubo and J. F. Kadla, J. Polym. Environ. 13 (2005) 97-105.

20. S. Hu and Y.L. Hsieh, J. Mater. Chem. A, 1 (2013) 11279.

21. V. Kalra, J. H. Lee, J. H. Park, M. Marquez and Y. L. Joo, Small, 5 (2009) 2323-2332.

22. X. Dong, M. Dong, Y. Lu, A. Turley, T. Jin, C. Wu, Ind. Crop. Prod. 34 (3) (2011) 1629 1634.

23. Z.M. Haung, Y.-Z. Zhang, M. Kotaki, S. Ramakrishna. Compos. Sci. and Tech., 63 (2003)

2223-2253.

\section{Figure captions}

Fig. 1. Schematic representation for the synthesis of PVA-lignin nanofiber mat loaded with silver nanoparticles.

Fig. 2. (A) Digital image of electrospun lignin nanofiber mat peeling from aluminium foil. (B) SEM image of lignin nanofiber at 10K-fold magnification, displaying the smooth and random orientation of nanofiber. (C) Energy dispersive X-ray spectroscopy spectrum of lignin nanofiber, showing the presence of silver metal ion at $2.9 \mathrm{keV}$. (D) Contact angle image of PLS nanofiber.

Fig. 3. TEM images of PVA-lignin-AGNP at different magnifications (A-F). (B) Showing the presence of silver nanoparticles on the surface of nanofiber. (C) Accumulation of nanoparticles inside of the fiber. (D) Faces of silver nanoparticles, suggesting the face cubic structure. (E-F) Distribution of nanoparticles on nanofiber surface.

Fig. 4. (A) XRD spectrum PVA-lignin-AGNP nanofiber mat, diffraction peaks at 33 and $47^{\circ}$ theta indicated the presence and FCC structure of silver nanoparticles. (B) Thermal degradation profile (TGA and DTA) of PVA-lignin-AGNP nanofiber mat. 
Fig. 5. Antimicrobial activity of PVA-lignin-AGNP nanofiber mat: (A) Ampicillin (at 20 $\mu \mathrm{g} / \mathrm{ml}$ ) (Control), Zone of inhibition against E.coli (B), B. Circulans (C). 


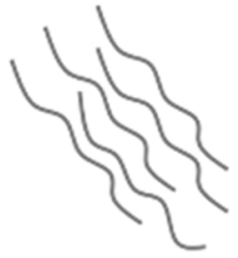

Lignin-PVA solution

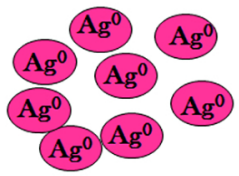

Pre synthesized

silver nanoparticles

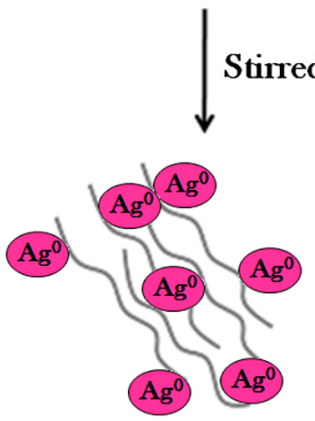

Electrospinning

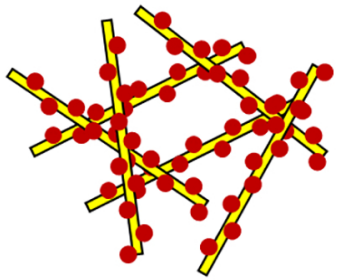

Lignin-PVAnanofibers incorporated with silver nanoparticles

Figure 1 


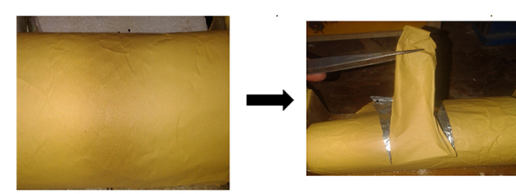

[A]
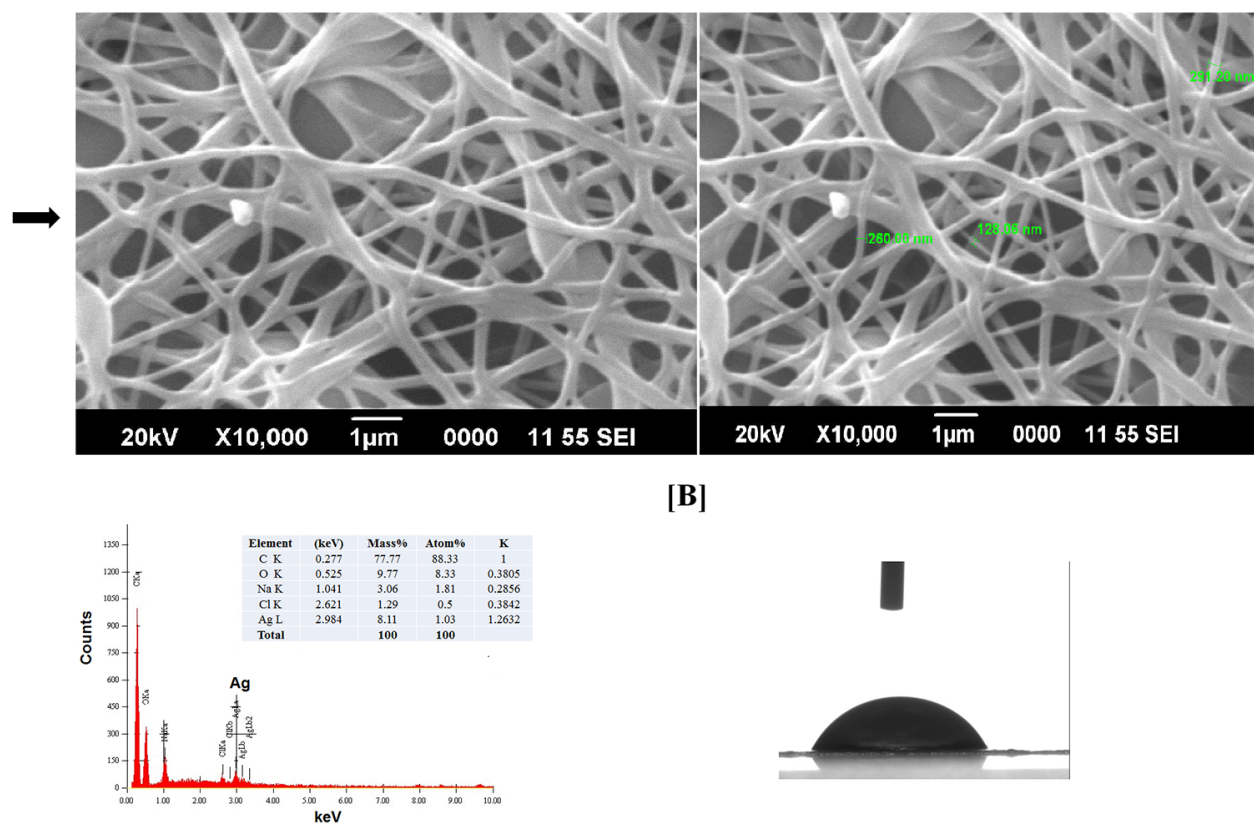

[B]

[C]

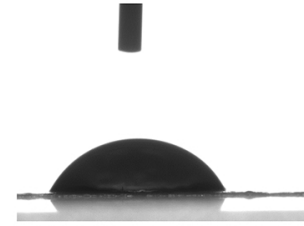

[D]

Figure 2 


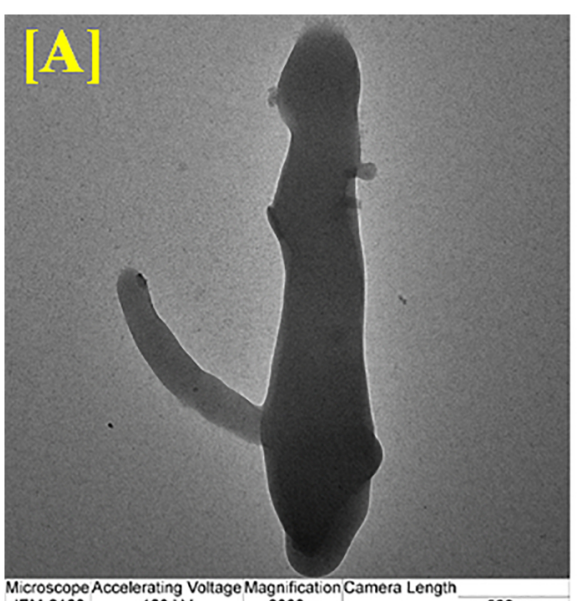

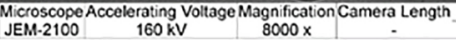

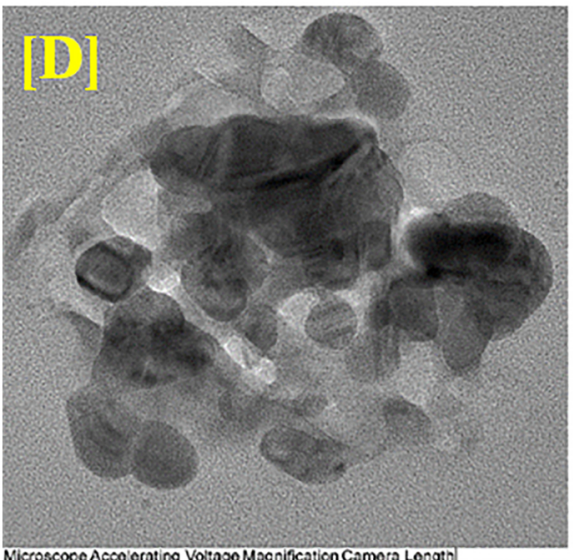

\section{[B]}

Silver

nanoparticles

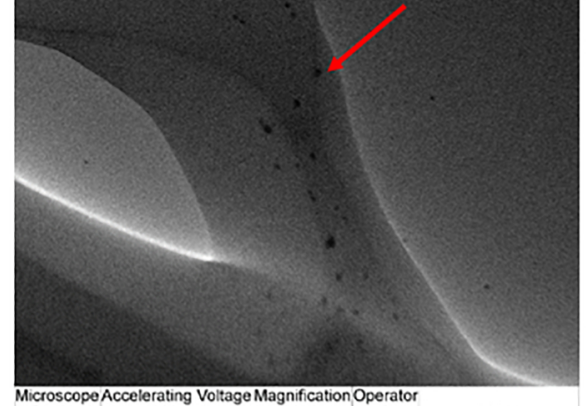

JEM-2100

$-100 \mathrm{~nm}-$

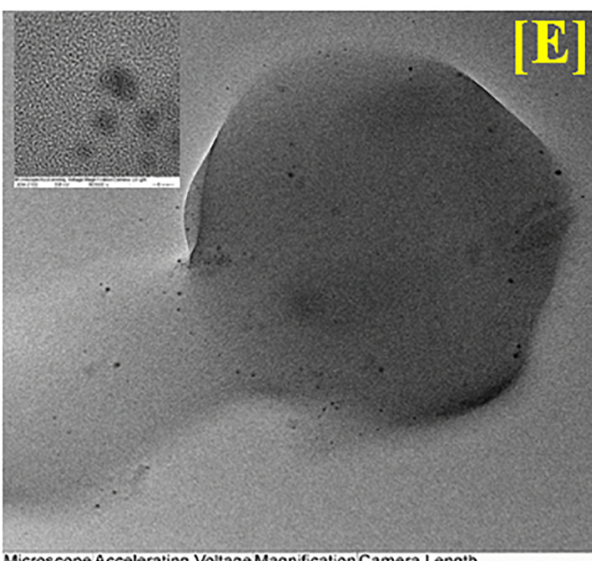

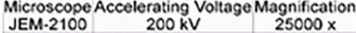

[C]

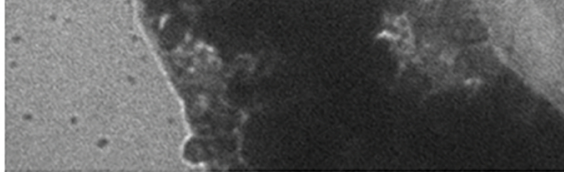

Microscope Accelerating Voltage Magnification Camera Length $160 \mathrm{kV} \quad 50000 x$

$-100 \mathrm{~nm}-$

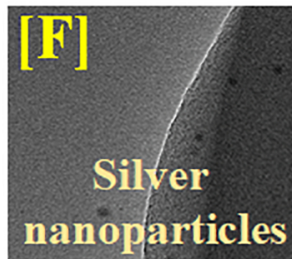

Microscope Accelerating Voltage Magnification Camera Length 


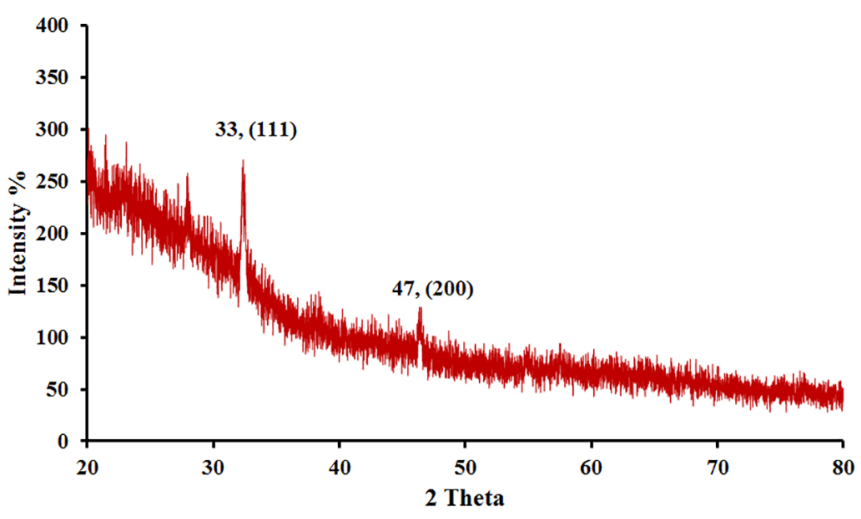

(A)

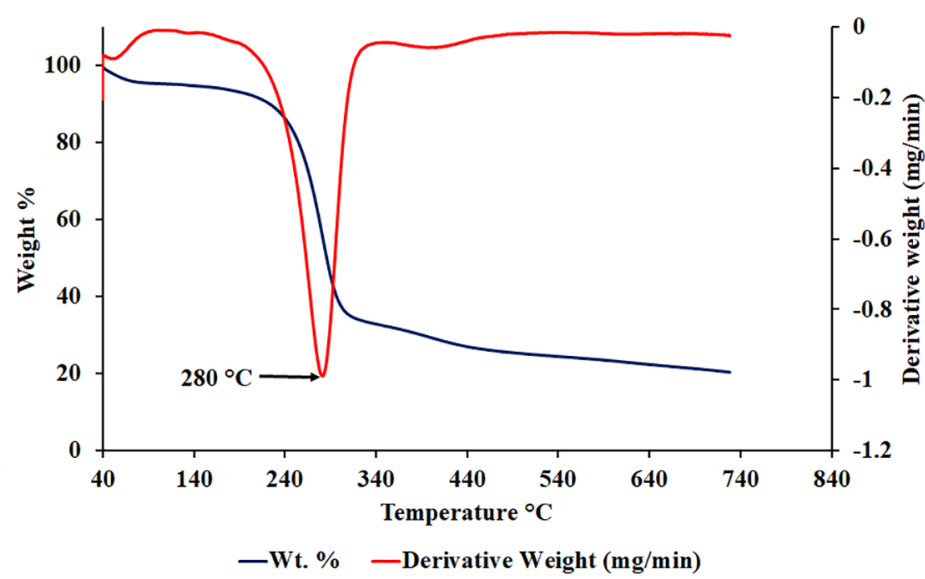

(B)

Figure 4 


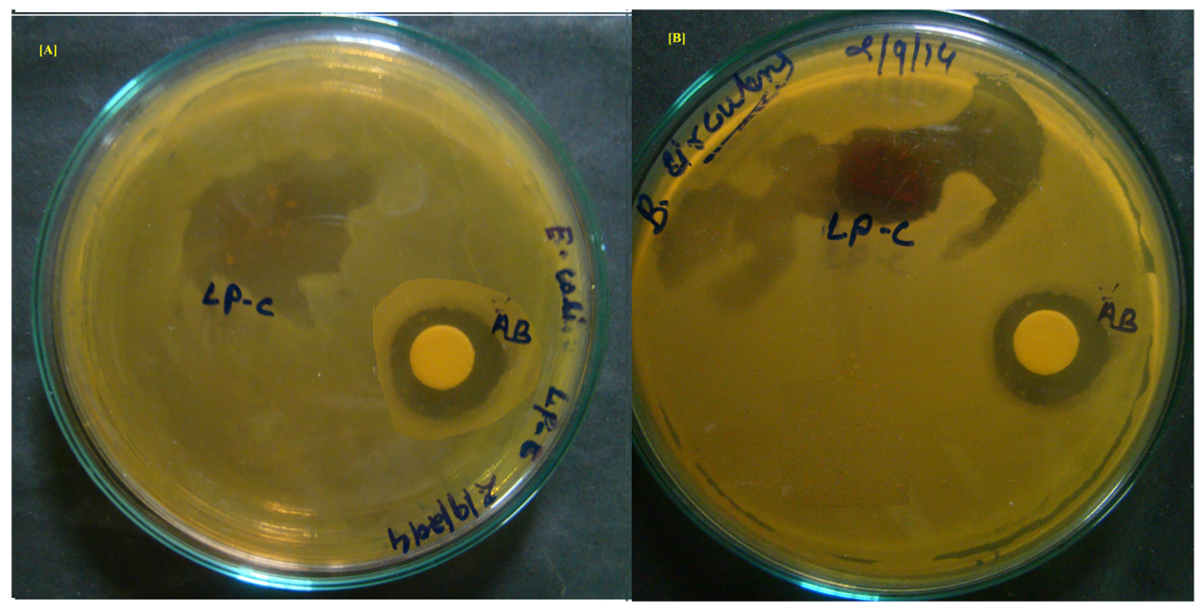

Figure 5 